\title{
MODEL ELECTRONIC WORD OF MOUTH DAN RATING DALAM MEMPENGARUHI MINAT BELIPADA MARKETPLACE SHOPEE PADA MASA PANDEMI COVID-19
}

\author{
Citra Savitri, Robby Fauji \\ citra.savitri@ubpkarwang.ac.id \\ robby.fauji@ubpkarwang.ac.id \\ Fakultas Ekonomi dan Bisnis, \\ Universitas Buana Perjuangan Karawang
}

\begin{abstract}
ABSTRAK
Tujuan penelitian ini adalah untuk menganalisis bagaimana pengaruh Electronic Word Of Mouth dan Rating terhadap Minat Beli pada Marketplace Shoppee pada Masa Pandemi Covid-19. Kemajuan teknologi informasi dan perubahan perilaku konsumen dalam memilih, menentukan dan menggunakan produk dan jasa menjadi salah satu alasan perusahaan untuk terus berkembang. Ketergantungan pada penggunaan internet dan perkembangan bisnis e-commerce di Indonesia terutama pada produk fesyen menjadi peluang untuk terus meningkatkan strategi bisnis yang dimiliki khususnya pada Marketplace Shoppee. Intensitas konsumen dalam penggunaan internet menjadi peluang bagi pebisnis digital untuk terus meningkatkan startegi dalam memasarkan produk dan jasa yang dimiliki.

Penelitian ini menggunakan metode analisis deskriptif verifikatif dengan analisis data menggunakan Path Analysis dengan teknik pengumpulan data menggunakan data melalui angket dan wawancara yang disebar kepada 189 responden. Hasil dari penelitian ini membuktikan bahwa $e$-wom, rating dan minat beli memiliki kriteria baik berdasarkan rentang skala. Sedangkan analisis verifikatif menyatakan bahwa $e$-wom memiliki pengaruh secara parsial terhadap minat beli tetapi tidak signifikan sedangkan rating memiliki pengaruh signifikan secara parsial terhadap minat beli. Sedangkanpengaruh simultan antara $e$-wom dan rating terhadap minat beli signifikan. Penelitian ini dapat memberikan kontribusi bagi marketplace yang ada di Indonesia untuk mengembangkan pola startegi pemasaran digital yang sesuai dengan kebutuhan dan keinginan konsumen.
\end{abstract}

KATA KUNCI: e-wom, rating, minat beli, Market Place.

\section{PENDAHULUAN}

Perkembangan teknologi, informasi dan ketergantungan internet telah merubah dan berevolusi dari WOM menjadi $e W O M$ yang disesuaikan dengan aplikasi dan pengaturan online pada berbagai saluran dalam bentuk ulasan produk, forum diskusi dan email yang terkait dnegan produk dan layanan (Brown, Broderick, \& Lee, 2007). Pada penelitian terdahulu $e W O M$ memberikan pengaruh pada kesuksesan produk yang berbasis internet, bagi dalam komunitas konsumen secara virtual, proses mempengaruhi perilaku kosnumen secara online melalui lingkungan dan komputer sebagai perantara pada media sosial dan situs jejaring sosial dan peningkatan penjualan sebagai dampak 
dari eWOM (Chevalier \& Mayzlin, 2003), (Yen \& Tang, 2019), (De Bruyn \& Lilien, 2008), (Savitri, Huriyati, \& Hendrayati, 2021).

Perubahan gaya hidup dan ketergantungan pada penggunaan internet menjadi peluang bagi para pemsar untuk memperkenalkan produk yang dimiliki dan sosialmedia menjadi platform paling tepat saat ini (Prasad, Gupta, \& Totala, 2017). Ulasan online yang merupakan bagian dari $e W O M$ yang memberikan kontribusi bagi parakonsumen untuk menggali informasi yang luas tentang pengalaman dengan produk atau layanan (Tallent-Runnels et al., 2006),(Gottschalk \& Mafael, 2017), (Aditya \& Waluyo,2020), (Savitri \& Khalida, 2019). Perkembangan bisnis digital di Indonesia ini tidak diimbangi dengan perkembangan ritel bisnis di dunia. Sejak tahun 2014 Indonesiatermasuk Negara dengan tingkat penjualan paling kecil dibanding Negara lainnya dimana Indonesia hanya mampu berada di peringkat 6 dari Negara yang ada di Asia sejak tahun 2014-2018 dengan tingkat penjualan $\$ 10.92$ triliun (eMarkerter, 2018).

Shoppee merupakan salah satu marketplace yang menawarkan produk fesyen pilihan yang menjadi favorit konsumen di Indonesia dengan menawarkan berbagai Top Brand pada produk dengan fitur promosi iklanku, promo toko, promo shoppee, voucher toko saya dan produk pilihan toko dianggap menjadi strategi pemasaran yang tepat (Shoppe, 2019). Strategi promosi tersebut membawa dampak terhadap peningkatantransaksi sejak tahun 2014-2018 secara signifikan dimana transaksi perdagangan digital meningkat $500 \%$ atau sebesar 144,1 triliun rupiah dengan jumlah popolasi sebesar 250 juta penduduk dengan platform pilihan terbanyak menggunakan jejaring sosial Facebook sebesar $43 \%$ (Databoks, 2016). Tingginya minat beli dan memberikan stimulus kepada konsumen untuk melakukan keputusan pembelian akan meningkatkan pula terjadi pembelian (Kotler, 2017).

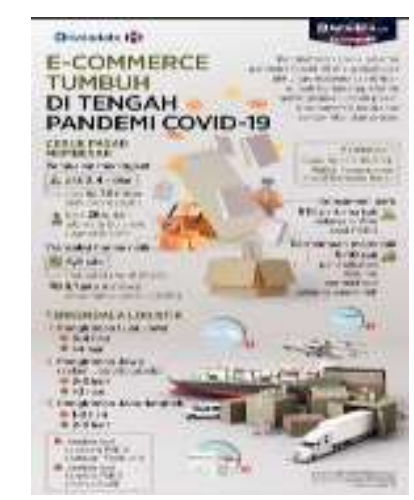

Sumber : (Pusparisa, 2020) 
Salah satu bisnis pada masa pandemi yang terus mengalami peningkatan penjualan adalah e-commerce terutama untuk ritel dan grosir. Penjualan berhasil meningkat sebesar US\$2,4 M dan rata-rata bulanan kuartal II -2019 mengalami peningkatan sebesar 26\% dengan transaksi harian sebanyak 4,8 juta ( sampai dengan april 2020). Salah satu alasan yang menyebabkan penjualan terus meningkat karena adanya rating.

Rating pada marketplace pun menjadi salah satu alasan konsumen untuk mempertimbangkan pilihan produk yang akan dipilih. Semakin baik rating maka peluangnya pun semakin besar dan berpengaruh terhadap minat beli (Ichsan, Jumhur, Hum, \& Dharmoputra, 2018). Masa pandemi covid-19 memberikan Penelitian ini bertujuan untuk menguraikan permasalahan penelitian tentang model $e$-wom dan rating dalam mempengaruhi minat beli pada marketplace Shoppee pada masa pandemi covid19.

\section{KAJIAN TEORI} $e-W O M$

Bentuk komunikasi pemasaran yang berisi tentang pernyataan positif dan negatif yang dilakukan para konsumen media internet yang berisi informasi yang dapatdiakses melalui sosial media seperti instagram, twitter, facebook (Mulyati, Haryeni, \& Masrur, 2018). Komunikasi yang dilakukan berupa rekomendasi, penilaian, tanggapan, pengalaman terkait produk dan jasa yang dapat menjadi pertimbangan dan mempengaruhi perilaku konsumen (Savitri \& Khalida, 2019), (Rianthong, Dumrongsiri, \& Kohda, 2016), (Lee, Park, \& Han, 2008), (Schiffman \& Wisenblit, 2005). Ada beberapa dimensi dalam e-wom antara lain : Intensity, Valence of Opinion, dan Content (Goyette I., Ricard, J., \& F., 2010).

\section{RATING}

Rating merupakan bentuk penilaian yang diberikan konsumen dari preferensi produk atau jasa yang telah dibeli terkait dengan hasil yang didapat. Rating dibuat oleh konsumen dan dipublikasikan pada website suatu survei atau lapak penjual yang mencerminkan secara global bagaimana konsumen dilayani oleh penjual (Engler, Winter, \& Schulz, 2015). Dimensi dari rating adalah : Purchase intention dan trust (Kotler, Keller, \& Manceau, 2015), (Vodicka, 2006).

\section{MINAT BELI}


Durianto (2013:58), mengungkapkan bahwa -Minat beli adalah keinginan untuk memiliki produk, minat beli akan timbul apabila seseorang konsumen sudah terpengaruh terhadap mutu dan kualitas dari suatu produk, informasi seputar produk, contoh: harga, cara membeli dan kelemahan serta keunggulan produk dibanding merek lain. Nugroho (2013:342) menjelaskan minat beli adalah proses pengintegrasian yang mengombinasikan pengetahuan untuk mengevaluasi dua atau lebih prilaku alternatif dan memilih salah satu diantaranya. Hasil dari proses pengintegrasian ini ialah suatu pilihan (choice), yang disajikan secara kognitif sebagai keinginan berperilaku. Dimensi pada minat beli adalah : minat transaksional, minat refrensial, minat prefensial dan minat eksploratif.

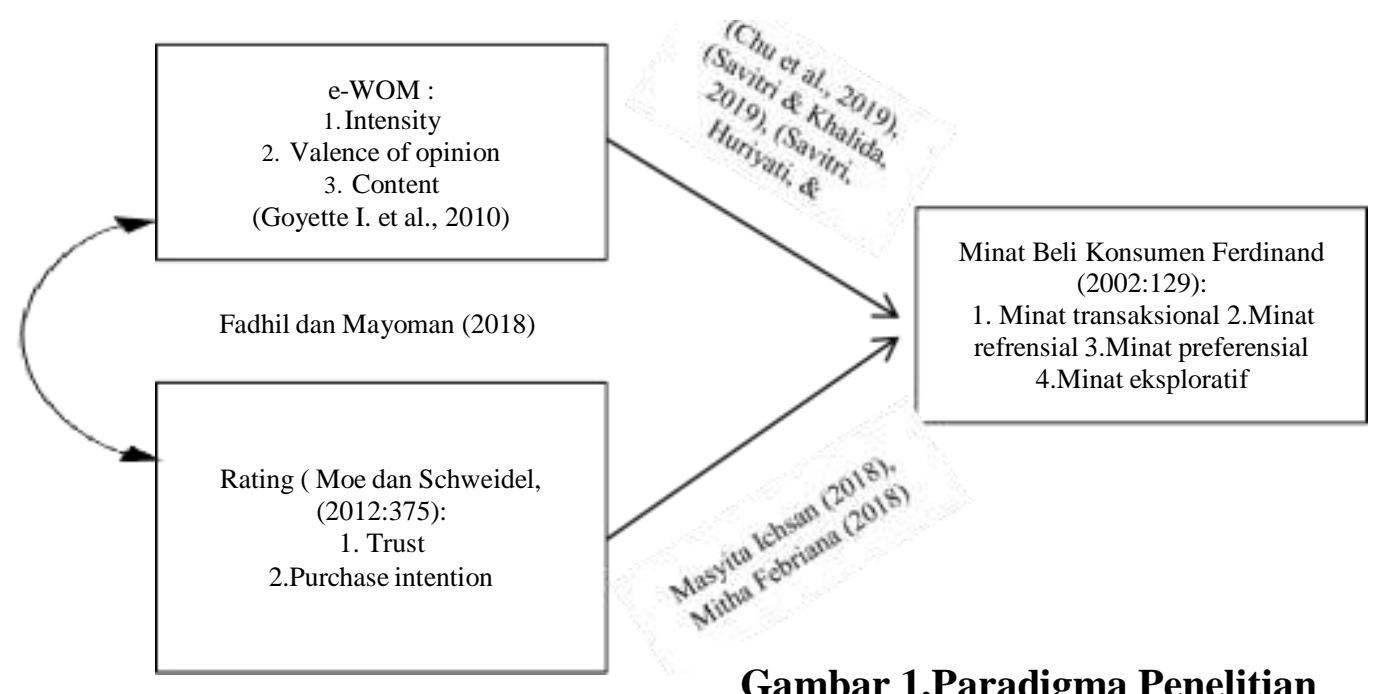

\section{METODE PENELITIAN}

Penelitian ini menggunakan metodologi pendekatan deskriptif verifikatif, yaitu untuk menganalisis pengaruh $e$-wom dan rating terhadap minat beli

Variabel dalam penelitian ini meliputi motivasi kerja dan kepuasan kerja. yang dijelaskan dengan indikator-indikator pada operasional sebagai berikut :

Tabel 1

Operasionalisasi Variabel

\begin{tabular}{lllll}
\hline No Variabel & Sub Variabel & Indikator & Skala & $\begin{array}{l}\text { No } \\
\text { Pernyataan }\end{array}$ \\
\hline & Intensity & $\begin{array}{l}\text { a. } \begin{array}{l}\text { Frekuensi } \\
\text { b. Intensitas } \\
\text { informasi }\end{array} \\
\end{array}$ & Ordinal & $1-2$ \\
& Positive valence & a. $\begin{array}{l}\text { banyaknya } \\
\text { ulasan }\end{array}$ & Ordinal & $3-4$ \\
\cline { 2 - 3 } & & \multicolumn{2}{c}{} &
\end{tabular}




\begin{tabular}{|c|c|c|c|c|c|}
\hline \multirow[t]{3}{*}{1} & \multirow[t]{3}{*}{$e W O M$} & \multicolumn{3}{|c|}{$\begin{array}{l}\text { positif } \\
\text { b. rekomendas } \\
\text { i positif }\end{array}$} & \multirow[b]{2}{*}{$5-6$} \\
\hline & & Negative valence & $\begin{array}{ll}\text { a. } & \text { banyaknya } \\
\text { ulasan } \\
\text { negatif } \\
\text { b. rekomendas } \\
\text { i negatif }\end{array}$ & Ordinal & \\
\hline & & WOM Content & $\begin{array}{ll}\text { a. } & \text { complain } \\
\text { pengguna } \\
\text { b. informasi } \\
\text { tentang } \\
\text { produk }\end{array}$ & Ordinal & $7-8$ \\
\hline \multirow[t]{2}{*}{2.} & rating & Trust & $\begin{array}{ll}\text { a. } & \text { consistency } \\
\text { b. } & \text { compassion } \\
\text { c. } & \text { communicat } \\
& \text { ion } \\
\text { d. } & \text { competency }\end{array}$ & Ordinal & $9-12$ \\
\hline & & Purchase intention & $\begin{array}{ll}\text { a. } & \text { ketertarikan } \\
\text { b. kepekaan } \\
\text { c. keinginan } \\
\text { d. tindakan }\end{array}$ & & $13-16$ \\
\hline
\end{tabular}

\begin{tabular}{|c|c|c|c|c|c|}
\hline \multirow{3}{*}{\multicolumn{2}{|c|}{$\begin{array}{ll}\text { 3. } & \text { Minat } \\
& \text { Beli }\end{array}$}} & $\begin{array}{l}\text { Minant } \\
\text { transaksional } \\
\text { Minat refrensial }\end{array}$ & 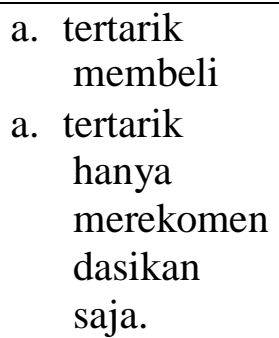 & $\begin{array}{l}\text { Ordinal } \\
\text { Ordinal }\end{array}$ & 17 \\
\hline & & Minat prefensial & $\begin{array}{l}\text { a. merekomen } \\
\text { dasikan } \\
\text { produk lain }\end{array}$ & Ordinal & 19 \\
\hline & & $\begin{array}{l}\text { Minat } \\
\text { eksploratif: }\end{array}$ & 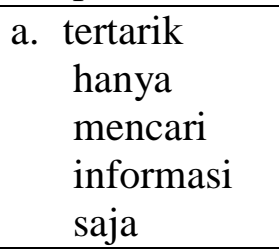 & Ordinal & 20 \\
\hline
\end{tabular}

Sumber: Olah data 2019

Populasi penelitian ini adalah seluruh pengunjung Shoppee dan sampel sebanyak 189 responden (Hair, Black, Babin, \& Anderson, 2010). Analisis data penelitian menggunakan metode deskriptif kualitatif dengan menggunakan analisis Path/Jalur. 


\section{HASIL DAN PEMBAHASAN}

\section{HASIL :}

\section{HASIL ANALISIS DESKRIPTIF}

Berdasarkan pengumpulan data yang dilakukan melalui angket penelitian didapatkan data angket sebagai berikut :

a. $e$-Wom

Berdasarkan hasil analisis deskriptif e-wom mencapai nilai total skor 5758 dengan nilai rata-rata skor 719,75 berada pada nilai rentang skala 642,6 - 793,8 dengan kategori setuju.

\section{b. Rating}

Berdasarkan hasil analisis deskriptif rating mencapai nilai total skor 6035 dengan nilai rata-rata skor 754,375 berada pada nilai rentang skala 642,6 - 793,8 dengan kategori setuju.

c. Minat Beli

Berdasarkan hasil analisis deskriptif rating mencapai nilai total skor 2718 dengan nilai rata-rata skor 679,5 berada pada nilai rentang skala 642,6 - 793,8 dengan kategori setuju.

2. HASIL ANALISIS VERIFIKATIF

Analisis verifikatif menggunakan analisis path.

1) Analisis Uji Validitas

Berdasarkan hasil pengolahan data dengan menggunakan program SPSS, diperoleh hasil uji validitas variabel $e$-wom $(\mathrm{X} 1)$, rating $(\mathrm{X} 2)$ dan minat beli (Y) seperti ditunjukan pada tabel berikut ini :

Tabel 2. Uji Validitas

\begin{tabular}{cccc}
\hline $\begin{array}{c}\text { No } \\
\text { Pernyataan }\end{array}$ & r hitung & r kritis & Kriteria \\
\hline 1 & 0.789 & 0,3 & Valid \\
2 & 0.79 & 0,3 & Valid \\
3 & 0.787 & 0,3 & Valid \\
4 & 0.794 & 0,3 & Valid \\
5 & 0.795 & 0,3 & Valid \\
6 & 0.811 & 0,3 & Valid
\end{tabular}


Citra Savitri, Robby Fauji

Vol 6 No 1

ISSN : 2541-6995

E ISSN : 2580-5517

Tabel 3. Lanjutan Uji Validitas

\begin{tabular}{cccc}
\hline $\begin{array}{c}\text { No } \\
\text { Pernyataan }\end{array}$ & r hitung & r kritis & Kriteria \\
\hline 7 & 0.817 & 0,3 & Valid \\
8 & 0.803 & 0,3 & Valid \\
9 & 0.838 & 0,3 & Valid \\
10 & 0.855 & 0,3 & Valid \\
11 & 0.834 & 0,3 & Valid \\
12 & 0.834 & 0,3 & Valid \\
13 & 0.834 & 0,3 & Valid \\
14 & 0.845 & 0,3 & Valid \\
15 & 0.843 & 0,3 & Valid \\
16 & 0.840 & 0,3 & Valid \\
17 & 0.866 & 0,3 & Valid \\
18 & 0.842 & 0,3 & Valid \\
19 & 0.936 & 0,3 & Valid \\
20 & 0.823 & 0,3 & Valid \\
\hline
\end{tabular}

Sumber data olah 2020

Berdasarkan tabel 2 uji validitas setiap variabel dapat dinyatakan valid. Hal ini dapat dibuktikan rxy hitung setiap indikator pada masing-masing variabel $>\mathrm{r}$ kritis. $\mathrm{r}$ kritis yang digunakan adalah 0,3 .

2) Analisis Uji Reliabilitas

Tabel 4. Uji Reliabilitas

\begin{tabular}{cccc} 
Variabel & R $_{\text {Hitung }}$ & R $_{\text {Kritis }}$ & Keterangan \\
\hline E-wom (X1) & 0,819 & & Reliabel \\
Rating (X2) & 0,857 & 0,7 & Reliabel \\
Minat Beli (Y) & 0,897 & & Reliabel
\end{tabular}

Sumber : Hasil pengolahan data kuesioner, SPSS, 2020 
3) Uji Normalitas

Berdasarkan hasil pengolahan data dengan menggunakan program SPSS diperoleh hasil uji normalitas data sebagai berikut :

Tabel 5. Uji Normalitas Variabel

\begin{tabular}{cccc}
\hline & \multicolumn{2}{c}{$\begin{array}{c}\text { Kolmogorov- } \\
\text { Variabel }\end{array}$} & \multicolumn{2}{c}{ Kesimpulan } \\
\cline { 2 - 3 } & p-value & $\boldsymbol{\alpha}$ & \\
\hline E-wom (X1) & 0,895 & 0,05 & Dist. Normal \\
Rating (X2) & 1,150 & 0,05 & Dist. Normal \\
Minat Beli (Y) & 1,384 & 0,05 & Dist. Normal \\
\hline
\end{tabular}

Sumber : Hasil pengolahan data kuesioner, SPSS, 2020

Tabel di atas menunjukkan bahwa semua variabel mengikuti sebaran data normal karena nilai p-value semua variabel $>0,05$.

4) Analisis Verifikatif dan Uji Hipotesis

Analisis uji verifikatif diperlukan untuk menguji besaran hubungan dan pengaruh masing-masing variabel sesuai yang dikemukakan pada perumusan masalah dan menguji hipotesisnya.

5) Analisis Korelasi Produk Moment

Besaran Korelasi Antara Variabel Bebas

Adapun nilai besaran hubungan antara variabel $e$-wom (X1) dan Rating (X2) dapat dijelaskan sebagai berikut :

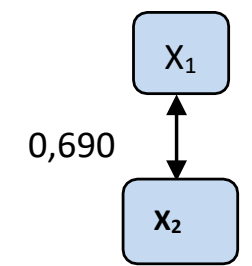

\section{Gambar 2.Korelasi di Antara Variabel Bebas}

Sumber : Hasil pengolahan data kuesioner, SPSS, 2020

Berdasarkan hasil analisis korelasi, diperoleh besaran koefisien korelasi diantara variabel bebas yaitu hubungan antara E-wom $\left(\mathrm{X}_{1}\right)$ dengan Rating $\left(\mathrm{X}_{2}\right)$ didapat nilai 
sebesar 0,690 yang berarti mempunyai tingkat hubungan yang kuat dan searah karena nilainya positif. Hal ini sesuai dengan tabel keeratan hubungan variabel yang dikemukakan (Sugiono, 2016).

Pengaruh Secara Parsial Variabel e-wom (X1) dan rating (X2) terhadap Variabel Minat Beli (Y)

Pengaruh secara parsial variabel $\mathrm{X}$ terhadap variabel $\mathrm{Y}$ dapat digambarkan seperti yang tampak dalam gambar di bawah ini :

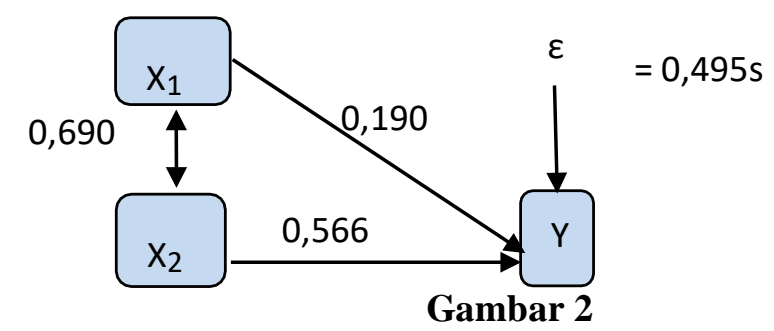

\section{Gambar 3.Pengaruh Parsial Variabel X1, X2 terhadap Variabel Y}

Sumber : Hasil pengolahan data kuesioner, SPSS, 2020

Dari gambar di atas, dapat kita jelaskan besaran derajat asosiatif atau koefisien jalur dari masing - masing variabel bebas terhadap variabel terikat dan persamaan jalurnya, yaitu:

$$
Y=0,190 X_{1}+0,566 X_{2}+\varepsilon
$$

\section{KESIMPULAN DAN IMPLIKASI}

\section{KESIMPULAN}

Berdasarkan hasil analisis dan pembahasan dapat ditarik kesimpulan sebagai berikut:

1. Berdasarkan hasil analsis deskriptif hampir semua responden memberi respon setuju atau baik. Namun terdapat 3 indikator yang menurut persepsi konsumen masih cukup baik atau ragu ragu, yaitu pada indikator ulasan negatif, rekomendasi negatif dan complain artinya konsumen memberikan respon yang cukup baik tetapi belum optimal terhadap beberapa indikator yang diterapkan selama ini oleh Marketplace Shopee.

2. Korelasi e-wom dengan rating mempunyai nilai koefisien korelasi (r) sebesar 0,690 dan jika diinterpretasikan dengan keeratan hubungan kedua variabel ini mempunyai tingkat hubungan yang kuat dan searah karena nilainya positif.

3. e-wom secara parsial berpengaruh tetapi tidak signifikan terhadap Minat Beli. Sedangkan Rating secara parsial berpengaruh signifikan terhadap Minat Beli. 
4. Terdapat pengaruh yang signifikan antara $e$-wom dan rating secara simultan

\section{IMPLIKASI}

Implikasi dari penelitian ini adalah Marketplace Shopee diharapkan untuk selalu meningkatkan kualitas produk yang dijual, menignkatkan pengguna sebagai penjual yang terverifikasi dan mengurangi pengguna yang menagakibatkan kerugian pengguna lain untuk meningkatkan respon pada indikator ulasan negatif, rekomendasi negatif dan complain di marketplace Shopee.

\section{REFERENSI}

Aditya, U. N., \& Waluyo, M. (2020). Analisis Hubungan Faktor-Faktor Electronic Word of Mouth Dalam Proses Keputusan Pembelian Mitsubishi Xpander. Juminten, 1(2), 81-92. https://doi.org/10.33005/juminten.v1i2.52

Brown, J., Broderick, A. J., \& Lee, N. (2007). Word Of Mouth Communication Within Online Communities. Journal of Interactive Marketing, 21(3), 2-21. https://doi.org/10.1002/dir

Chevalier, J. a, \& Mayzlin, D. (2003). the Effect of Word of Mouth on Sales : National Bureau of Economic Research, 40. https://doi.org/10.1509/jmkr.43.3.345

Databoks. (2016). Transaksi E-Commerce Indonesia Naik 500\% dalam 5 Tahun.

Retrieved from Katadata website:

https://databoks.katadata.co.id/datapublish/2016/11/16/transaksi-e-commerceindonesia-naik-500-dalam-5-tahun

De Bruyn, A., \& Lilien, G. L. (2008). A Multi-Stage Model of Word of Mouth Through Electronic Referrals. International Journal of Research in Marketing, 25, 151-163. eMarkerter. (2018). Data Penjualan Ritel Online. Retrieved from www.emarketer.com/Article/Asia-Pacific-Home-Majority-of-World-RetailEcommerce-Market, 2016

Engler, T. H., Winter, P., \& Schulz, M. (2015). Understanding online product ratings: A customer satisfaction model. Journal of Retailing and Consumer Services, 27, 113-120. https://doi.org/10.1016/j.jretconser.2015.07.010

Gottschalk, S. A., \& Mafael, A. (2017). Cutting Through the Online Review Jungle Investigating Selective eWOM Processing. Journal of Interactive Marketing, 37, 89-104. https://doi.org/10.1016/j.intmar.2016.06.001 
Goyette I., Ricard, L., J., B., \& F., M. (2010). e-WOM Scale: word-of-mouth measurement scale for e-services context. Canadian Journal of Administrative Sciences/Revue Canadienne Des Sciences de l'Administration, 27(1), 5-23.

Hair, J., Black, W., Babin, B., \& Anderson, R. (2010). multivariate data analysis (Global Edi). Pearson Higher Education Upper.

Ichsan, M., Jumhur, H. M., Hum, M., \& Dharmoputra, I. S. (2018). Pengaruh Consumer Online Rating and Review Terhadap Minat Beli Konsumen Pada Marketplace Tokopedia Di Wilayah Dki Jakarta Effect of Consumer Online Rating and Review To Buying. E-Proceeding of Management, 5(2), 1828-1835.

Kotler, P. (2017).[Philip_Kotler]_Kotler,_P.,_2017._Marketing_4.0_Mo(z-lib.org) (14th ed.). Prentice Hall.

Kotler, P., Keller, K. L., \& Manceau. (2015). Marketing Management. Retrieved from

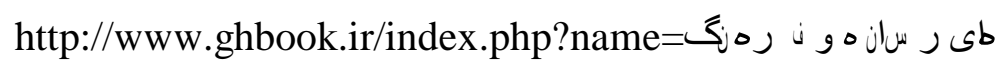
ن ون ن i\&option=com_dbook\&task=readonline\&book_id=13650\&page=73\&chkhash k=ED9C9491B4\&Itemid=218\&lang=fa\&tmpl=component

Lee, J., Park, D. H., \& Han, I. (2008). The effect of negative online consumer reviews on product attitude: An information processing view. Electronic Commerce Research and Applications, 7(3), 341-352. https://doi.org/10.1016/j.elerap.2007.05.004

Mulyati, Y., Haryeni, \& Masrur. (2018). Pengaruh Electronic Word Of Mouth Terhadap Citra Destinasi Serta Dampaknya Pada Minat Dan Keputusan Berkunjung Wisatawan Domestik Pada Destinasi Wisata Kota Bukit Tinggi. Jurnal Ekonomi \& Bisnis Dharma Andalas, 20(1), 168-187.

Prasad, S., Gupta, I. C., \& Totala, N. K. (2017). Social media usage, electronic word of mouth and purchase-decision involvement. Asia-Pacific Journal of Business Administration, 9(2), 134-145. https://doi.org/10.1108/APJBA-06-2016-0063

Pusparisa, Y. (2020). E-Commerce Tumbuh di Tengah Pandemi Covid-19 Artikel ini telah tayang di Katadata.co.id dengan judul -E-Commerce Tumbuh di Tengah Pandemi Covid-19.|l Retrieved from katadata.co.id website: https://katadata.co.id/ariayudhistira/infografik/5ec48b7f099d1/e-commercetumbuh-di-tengah-pandemi-covid-19

Rianthong, N., Dumrongsiri, A., \& Kohda, Y. (2016). Improving the multidimensional 
sequencing of hotel rooms on an online travel agency web site. Electronic Commerce Research and Applications, 17, 74-86.

https://doi.org/10.1016/j.elerap.2016.03.002

Savitri, C., Huriyati, R., \& Hendrayati, H. (2021). The power of EWOM for online business. Advances in Business, Management and Enrepreneurship, 4(1), 329-331.

Savitri, C., \& Khalida, L. R. (2019). Pengaruh e-Wom pada Bisnis Online. 5(1). Retrieved from https://doi.org/10.36805/manajemen.v5i1.970

Schiffman, L. G., \& Wisenblit, J. (2005). Consumer Consumer Behavior Behavior Consumer Consumer Behavior Behavior.

Shoppe. (2019). No Title.

Sugiono. (2016). Metode Penelitian Kuantitatif, Kualitatif, Dan R\&D. Bandung: Alfabeta.

Tallent-Runnels, M. K., Thomas, J. A., Lan, W. Y., Cooper, S., Ahern, T. C., Shaw, S. M., \& Liu, X. (2006). Teaching courses online: A review of the research. Review of Educational Research, 76(1), 93-135. https://doi.org/10.3102/00346543076001093

Vodicka, D. (2006). The Four Elements of Trust. Principal Leadership, 7(3), 27-30. Retrieved from https://www.nassp.org/portals/0/content/54439.pdf

Yen, C. L. A., \& Tang, C. H. H. (2019). The effects of hotel attribute performance on electronic word-of-mouth (eWOM) behaviors. International Journal of Hospitality Management, 76(September 2017), 9-18. https://doi.org/10.1016/j.ijhm.2018.03.006 